\title{
La religión secreta de los alemanes: panteísmo y revolución en la Alemania decimonónica (1831-1848). Segunda parte
}

\section{The Germans' Secret Religion: Pantheism and Revolution in Nineteenth-Century Germany (1831-1848). Part 2}

\author{
Héctor del Estal Sánchez ${ }^{1}$ \\ Universidad de Salamanca (España)
}

Recibido: 13-05-19

Aprobado: 09-10-19

\section{Resumen}

En este trabajo utilizaremos la tipología schmittiana de pares conceptuales teológico-políticos como marco interpretativo para estudiar cómo el panteísmo fue considerado en la Alemania decimonónica (especialmente entre 1831 y 1848) como una doctrina revolucionaria en un sentido político. En esta segunda parte, analizaremos tanto los debates sobre la personalidad de Dios surgidos a raíz de la publicación de Das Leben Jesu de Strauß como la plasmación del proyecto político revolucionario vinculado al panteísmo en la izquierda hegeliana a través de una de sus figuras representativas: Heinrich Heine.

Palabras-clave: panteísmo, personalidad de Dios, revolución, izquierda hegeliana, Heinrich Heine, Carl Schmitt.

\footnotetext{
${ }^{1}$ (hedesa@usal.es) Profesor asociado del Departamento de Filosofía, Lógica y Estética de la Facultad de Filosofía de la Universidad de Salamanca. Sus líneas de investigación se centran en filosofía de Arthur Schopenhauer y su escuela, la filosofía de la historia, la filosofía política alemana del siglo XIX y la historia conceptual. Algunas de sus publicaciones recientes son: "Ornithorhynchus Paradoxus: la recepción de la filosofía de Arthur Schopenhauer entre 1818 y 1848 " en Revista Anales del Seminario de Historia de la Filosofía 35 (1), 127-156, "Identidad y compensación en el nacionalismo cultural alemán en la época de la República de Weimar" en Revista de Filosofía 44 (1), 43-59 y "Tendencias realistas en la filosofía de Arthur Schopenhauer. Valoración y crítica desde el punto de vista del Nuevo Realismo" en Estudios Filosóficos 69 (200), 87-109.

ORCID: https://orcid.org/0000-0003-0827-4076.
} 


\begin{abstract}
In this essay we will use the schmittian typology of theological-political conceptual pairs as conceptual framework to study how pantheism was considered in nineteenth-century Germany (particularly between 1831 and 1848) as a revolutionary political doctrine. In this second part, we will analize the discussions about God's personality that followed the publishing of Strauß's Das Leben Jesu as well as the embodiment of the revolutionary political project related to pantheism in Hegelian left through one of its most representative figures: Heinrich Heine.
\end{abstract}

Key-words: Pantheism, God's Personality, Revolution, Left Hegelians, Heinrich Heine, Carl Schmitt.

\title{
4. El problema de la personalidad de Dios. Un debate entre la teología política restauracionista y una filosofía (política) de la religión.
}

He elegido aquí la personalidad de Dios y la inmortalidad del alma porque son precisamente estos temas sobre los que, incluso entre los seguidores de la filosofía más reciente, ha surgido la mayor divergencia de puntos de vista; tanto es así, que la historia de la filosofía en los últimos diez años es en realidad solo la historia de las disputas planteadas en el curso de la filosofía sobre estos temas $^{2}$.

Con estas palabras, el hegeliano Michelet describía en 1840 cuál era la discusión candente en el ámbito de la filosofía alemana. No le faltaba razón: si una obra puso en pie de guerra a los ideólogos de la teología política restauracionista, esa fue Das Leben Jesu kritisch bearbeitet (1835-36) de David Friedrich Strauß. En ella, tanto los progresistas Junghegelianer como los teóricos políticos conservadores vieron claramente las consecuencias políticas del panteísmo: los primeros recibieron con júbilo la constatación y el reconocimiento del potencial revolucionario de un hegelianismo panteísta; los segundos vieron en ello la ocasión perfecta para esgrimir sus plumas en la lucha contra las ideas políticas revolucionarias.

Por lo que respecta a los Junghegelianer, éstos vieron claramente que el pensamiento político que sustentaba la Restauración se apoyaba por completo en el concepto religioso de la personalidad divina y su trasvase al terreno político, bien como una relación de participación, bien como una análoga. Los años de paciente espera de reforma, de ardiente voz reprimida y de esperanza

\footnotetext{
${ }^{2}$ Carl Ludwig Michelet, Vorlesungen über die Persönlichkeit Gottes und Unsterblichkeit der Seele oder die ewige Persönlichkeit des Geistes. Gehalten an der Friedrich-Wilhelms-Universität zu Berlin im Sommerhalb-Jahre 1840, Berlin, Ferdinand Bümmler, 1841, p. 7.
}

Araucaria. Revista Iberoamericana de Filosofia, Politica, Humanidades y Relaciones Internacionales, año $22, \mathrm{n}^{\circ} 44$. Segundo semestre de 2020. Pp. 107-124. ISSN 1575-6823 e-ISSN 2340-2199 https://dx.doi.org/10.12795/araucaria.2020.i44.05 
en una revolución "desde arriba" - el propio Hegel, según el testimonio de Heine, habría participado de esta paciencia hambrienta de revolución ${ }^{3}$ - habían acabado con la muerte del gran filósofo en Berlín en 1831. Ahora veían claramente que el panteísmo era un arma política en un doble sentido: por una parte, podían escapar de la censura disfrazando la política de religión y, por otra, eran plenamente conscientes de que, dado el espíritu de las teorías políticas de la Restauración, el campo de batalla era el religioso. El uso efectivo del panteísmo como herramienta política al servicio de los ideales liberales y democráticos que tanto tiempo llevaba gestándose salía por fin a la luz con la obra de Strauß.

Si embargo, el año 1831 también marcó el comienzo de una "cacería" de las ideas políticas revolucionarias que a comienzos de la década de los 40 acabaría situando a la filosofía hegeliana en el punto de mira no solo de los pensadores restauracionistas, sino también de las propias autoridades políticas de la Restauración.

4.a) El detonante. Das Leben Jesu kritisch bearbeitet (1835-36) de David Friedrich Strauß y la divinización del ser humano

En Das Leben Jesu kritisch bearbeitet, David Friedrich Strauß emprendía un estudio de la figura histórica de Jesús en contraposición a la religiosa, catalizando así la tradición crítica del spinozismo clandestino en torno a las Escrituras sirviéndose del poderoso aparato conceptual de la filosofía hegeliana. El resultado de aplicar las categorías hegelianas a la crítica del contenido de la religión positiva fue que el relato de la vida y hechos de Jesús recogido en los Evangelios debía situarse en el ámbito del mito. Sin embargo, el punto central para la polémica -si esto no fuese acaso motivo suficiente para despertar la acostumbrada cólera de los teólogos ortodoxos- lo constituyó la cuestión de la personalidad divina encarnada en Jesús, piedra de toque de la política restauracionista.

Para Strauß las religiones positivas eran, al modo hegeliano, distintos momentos de expresión y realización de la Razón, del Espíritu que guía el mundo. ¿Cómo conciliar esto con la fe ortodoxa? La armonización era imposible debido a la superioridad que, en la filosofía hegeliana, se otorgaba a la filosofía respecto

\footnotetext{
${ }^{3}$ En un borrador manuscrito para el prólogo de la edición de 1844 de Sobre la historia de la religión y de la filosofía en Alemania, Heine nos lega este recuerdo con el que aleja a Hegel de la tesis del acomodacionismo al Estado prusiano: "Una vez que me impacienté contra la sentencia 'todo lo real es racional', él [Hegel] sonrió curiosamente y me hizo observar que eso también podía querer decir 'Todo lo que es racional tiene que ser real'. Miró ansiosamente en torno suyo, pero se tranquilizó al comprobar que sólo le había oído Heinrich Beer" (Heinrich Heine, Sobre la historia de la religión y de la filosofía en Alemania, Madrid, Alianza, 2008, p. 133n). También Domenico Losurdo se muestra contrario a la tesis de la acomodación en: Domenico Losurdo, Hegel, Marx e la tradizione liberale. Libertà, uguaglianza, Stato, Roma, Editori Riuniti, 1988, pp. 47-49.
}

Araucaria. Revista Iberoamericana de Filosofia, Política, Humanidades y Relaciones Internacionales, año $22, \mathrm{n}^{\circ} 44$. Segundo semestre de 2020. Pp. 107-124. ISSN 1575-6823 e-ISSN 2340-2199 https://dx.doi.org/10.12795/araucaria.2020.i44.05 
a la religión a la hora de representar y encarnar el Espíritu ${ }^{4}$ : el contenido de la fe, la verdad, quedaba absolutamente transformado en la reflexión hegeliana al adquirir un rango superior en la filosofía. Las consecuencias de esta visión son irreparables: por una parte, es incompatible entender que Dios media en el mundo en un determinado momento histórico del Espíritu en la figura de Cristo y que, al mismo tiempo, ese Cristo se corresponde precisamente con el de los Evangelios cuando éste representa allí la mitología propia del judaísmo de aquella época. Por otra -y aquí estalla la polémica- si Dios, la Razón, el Espíritu, se encarna y realiza de un modo progresivo en y a través de la historia, la figura de Jesús es única y exclusivamente un momento de ese proceso dentro de la humanidad en general. Dios sólo se encarna en el mundo de un modo completo en la humanidad a lo largo de la historia ${ }^{5}$.

La negación de la personalidad divina la expresa Strauß posteriormente - precisamente a colación de Spinoza- de un modo sumamente sintético en Die christliche Glaubenslehre (1840):

\begin{abstract}
Nos sabemos y sentimos como personas solo en diferencia con otras personas iguales fuera de nosotros, de las cuales nos diferenciamos; por lo tanto, [nos sabemos como personas] finitas. Creado por y para este espacio de la finitud, el concepto de personalidad parece perder consecuentemente aquel significado [fuera de él]; y un ser que no tiene a otro igual fuera de sí, tampoco puede ser ninguna persona. Hablar de un Dios personal o de una personalidad divina desde este punto de vista parece una combinación de conceptos que por definición se anulan y excluyen mutuamente ${ }^{6}$.
\end{abstract}

El personalismo divino quedaba así en entredicho por la simbiosis entre crítica a las Escrituras y filosofía hegeliana; simbiosis que daba lugar a una divinización panteísta del ser humano. No resulta sorprendente, dados los antecedentes en el período de la Ilustración, que la acusación de panteísmo y las reflexiones sobre las consecuencias políticas de Das Leben Jesu no se hiciesen esperar.

\footnotetext{
${ }^{4}$ Esto fue duramente criticado ya en 1830 por autores como Stahl: "Que la religión, según Hegel, no puede conocer en qué relación está con la filosofía, sino que solo la filosofía puede conocer en qué relación está consigo misma y con la religión, [es algo que] se entiende de suyo; pues la religión es, como tal, tan solo el incierto punto de entrada a través del cual Dios llega finalmente [al estadio de la] filosofía, donde puede comprender lo que realmente quería en los anteriores estadios. No se sorprenderá nadie, entonces, de que se haya desfigurado el cristianismo [...]" Friedrich Julius Stahl, Die Philosophie des Rechts. Erster Band. Geschichte der Rechtsphilosophie, Hildesheim, Georg Olms, 1963, p. 466. (Para nuestra traducción nos hemos apoyado en la realizada por Enrique Gil y Robles en: Friedrich Julius Stahl, Historia de la filosofia del derecho, Madrid, La España Moderna, s.a., p. 548).

${ }^{5}$ Cfr. Félix Duque, La Restauración. La escuela hegeliana y sus adversarios, Madrid, Akal, 1999, pp. 133-135.

${ }^{6}$ David Friedrich Strauß, Die christliche Glaubenslehre in ihrer geschichtlichen Entwicklung und im Kampfe mit der modernen Wissenschaft dargestellt. Erster Band, Tübingen/Stuttgart, C.F. Osiander/F. H. Köhler, 1840, p. 504
} 
4. b) El hegelianismo destronado. De la acusación de acomodacionismo a la enemistad con Prusia

Con la publicación de Das Leben Jesu, las cosas cambiaron radicalmente para el hegelianismo. Eduard Gans, el famoso discípulo de Hegel y profesor de derecho en Berlín, constata el cambio que se ha dado en la visión de la filosofía hegeliana desde la muerte del maestro:

Hasta el año 1832 reinaba en Alemania un griterío bien conocido que afirmaba de la filosofía de Hegel que era la filosofía oficial de Prusia porque alababa todo lo que resultaba de este gobierno y que, por ello, era favorecida: [se decía que] era una [filosofía] ultraortodoxa [dunkelorthodoxe], por lo cual, entonces, también los racionalistas la atacaron desde las estrechas trincheras de $s u$ razón; [también que] era infamemente servil, pues se atrevía incluso a afirmar que lo que era real, eso era racional. [...] Desde el año 1832 los ataques salen del otro lado con distintas artimañas. No ha sido aceptada ni como servil ni liberal, sino, por desgracia, solo como filosofía filosófica; no ha sido aceptada ni en el camino equivocado del pietismo ferviente [geilen Pietismus], ni en el castillo de aire de la obra faraónica de los Junker [Junkerpyramidenbaues], ni en la mala nueva fe de los buenos viejos tiempos. Se ha hecho finalmente tan incómoda como el liberalismo mismo ${ }^{7}$.

En efecto, la doctrina hegeliana se había vuelto peligrosa con el panteísmo. El primero en establecer una relación -si bien únicamente análoga- entre religión y política en torno a Das Leben Jesu fue precisamente un miembro de la derecha hegeliana: Friedrich Göschel ${ }^{8}$. En la crítica a la religión realizada por Strauß, en principio fuera de los márgenes de la política, Göschel entrevió la posibilidad de establecer nexos entre la personalidad de Dios (negada en el texto de Strauß) y la personalidad del monarca. No en vano, Altenstein, tratando de rescatar el hegelianismo de la explosiva polémica que se avecinaba, encargó a Göschel la redacción de una respuesta a Das Leben Jesu que acabó siendo publicada en 1838 bajo el título Beiträge zur spekulativen Philosophie von Gott und dem Menschen und von dem Gott-Menschen. Mit Rücksicht auf Dr. D. F. Strauss Christologie. Allí, Göschel reconoce claramente que el

${ }^{7}$ Eduard Gans, "Ueber die Unvereinbarkeit der Hegel'schen Staatslehre mit dem obersten Lebensund Entwickelungsprincip des preussischen Staats; von Dr. K.E.E. Schubarth. Breslau, 1839. Bei Georg Philipp Aderholz. 30 S. in 8" en Jahrbücher für Wissenschaftliche Kritik, 25-26 (febrero de 1839), p. 204. No es ni mucho menos anecdótico que, a este respecto, autores como Karl Friedrich Bachmann afirmasen en estos años que la filosofía hegeliana era un peligro para el Estado en términos absolutos. Para este autor, tal y como expresó en su Anti-Hegel, "no solo el despotismo monárquico, sino también el radicalismo extremo, el jacobinismo absoluto y el sansculotismo encuentran [en el dístico "todo lo racional es real; todo lo real es racional"] justificación y aprobación. [...]" (Karl Friedrich Bachmann, Anti-Hegel, Jena, Crokescher Buchhandlung, 1835, p. 150).

${ }^{8}$ Cfr. Warren Breckman, Marx, the Young Hegelians, and the Origins of Social Theory. Dethroning the Self, Cambridge, Cambridge University Press, 2001, pp. 134-137. 
panteísmo niega el concepto de personalidad: "Panteísmo no solo es cuando se priva de personalidad al individuo como si fuese un ser natural [cualquiera], sino que panteísmo es también, en la misma medida, cuando se contradice la personalidad [al considerar] la humanidad como si solo fuese una especie natural"'. Teniendo en cuenta la negación de la personalidad divina en el panteísmo, Göschel procede a realizar una defensa de la ortodoxia religiosa utilizando una analogía inversa a la comúnmente hecha por los pensadores conservadores en su teología política: del mismo modo que debe reconocerse que la personalidad del cuerpo político, del Estado, depende en última instancia de la personalidad real del monarca, la personalidad de la humanidad sólo puede reconocerse a través de la personalidad real de Dios en Cristo. Para Göschel, la humanidad entendida como comunidad espiritual, tal y como la haría Strauß, únicamente tiene una personalidad moral, pero no personalidad real:

\begin{abstract}
Según Strauß la idea de Cristo en su totalidad tiene únicamente su personalidad en todo el género humano; algo así como si la idea del derecho tuviese su personalidad en el Estado. Por eso nosotros atribuimos con razón al Estado, como a un todo, una personalidad moral o mística para apresar su unidad, es decir, para comprenderla. Es sin embargo completamente cierto que esta idea mística de personalidad, únicamente como subjetiva o moral, todavía no es un concepto efectivamente real, sino que solo puede tener validez como su precursora. La personalidad moral del Estado es por lo tanto el comienzo típico de su concepto: para adquirir personalidad real debe primero tomar la forma que nosotros llamamos monarquía; y esta monarquía es precisamente por eso la más perfecta formación del Estado porque en ella la personalidad moral no permanece en sí, sino que llega a la realidad efectiva en un individuo y, en consecuencia, a su determinación $n^{10}$.
\end{abstract}

Así Göschel, evidenciando que la personalidad divina era análoga a la personalidad del monarca por un camino inverso al habitual (es decir, tratando de demostrar que se debía atribuir personalidad a Dios como soberano del mismo modo que se le atribuye al monarca como soberano del Estado) había puesto de manifiesto lo que estaba en juego con el panteísmo straußiano: la legitimación y el fundamento teológicos que servían de base al régimen de la Restauración.

El establecimiento de esta relación fue aplaudido -como señalamos-tanto por los Junghegelianer como por los políticos conservadores ${ }^{11}$ : si la relación de la analogía se invertía, entonces resultaba que negar la personalidad de Dios era para la teología política de los antirrevolucionarios, a fin de cuentas,

\footnotetext{
${ }^{9}$ Carl Friedrich Göschel, Beiträge zur spekulativen Philosophie von Gott und dem Menschen und von dem Gott-Menschen. Mit Rucksicht auf Dr. D. F. Strauss Christologie, Berlín, Duncken und Humboldt, 1838, p. 193 y s.

${ }^{10}$ Ibidem, p. 60.

${ }^{11}$ Cfr. Warren Breckman, op. cit., p. 14.
} 
deslegitimar el sustento personal de la autoridad del monarca; la cual otorgaba realidad efectiva al Estado de la Restauración. El propio texto de Göschel lo dejaba claro:

Queremos invertir el ejemplo tomado del Estado [...]. El monarca en el Estado no es el monarca de la humanidad [Dios]; en consecuencia, tampoco es más que ningún otro hombre; sin embargo, él es el monarca del Estado, [...] está sobre el Estado, pero por eso no es, sin embargo, tan independiente del Estado como el monarca de la humanidad [Dios] lo es de la humanidad como hombre originario [Ur-Mensch]. No obstante, el monarca mantiene también, en la medida en que sostiene una relación terrena, una independencia del Estado, pues no pertenece al Estado y a su organismo como si fuese un miembro corporal, sino que él es también como la cabeza [Haupt] sobre el Estado: él es el único en el Estado que no es súbdito, y por ello, [es] esencialmente absoluto; también por eso no deja de ser monarca incluso cuando él no es reconocido como consecuencia de un tiempo insurrecto; aunque [bien es cierto que] su monarquía solo comienza a existir después de su dignidad personal si él es al mismo tiempo reconocido, y solo es perfecta si ha conseguido una comunidad permeable con todos sus súbditos ${ }^{12}$.

La trampa panteísta al Ancien Régime había sido descubierta; y los ideólogos conservadores de la Restauración dirigieron, bajo el visto bueno del gobierno prusiano, sus más feroces ataques contra los hegelianos panteístas. Cuando en 1840 Federico Guillermo IV asciende al trono, la polémica está en pleno auge y llama a sus primeros espadas en la causa personalista contra el panteísmo: Friedrich Julius Stahl es llamado a ejercer como profesor de derecho en la Universidad de Berlín para ocupar la vacante del recién fallecido Eduard Gans; y, al año siguiente, también lo es Schelling para la cátedra de filosofía. La carta del Barón von Bunsen dirigida a este último, muestra claramente la intención del monarca:

El rey siente, más fuerte y profundamente de lo que lo hacía como príncipe heredero, la miseria hacia la que la querida patria se ha precipitado a causa del estancamiento y envilecimiento de toda vida real en el Estado y la Iglesia, y de la arrogancia y el fanatismo de la escuela [hegeliana] del concepto vacío. Desde hace tiempo se ha dado cuenta y ha experimentado cómo estas circunstancias unidas han desarrollado en una parte de los más jóvenes una fuerza corrosiva y destructiva que recuerda a épocas y peligros que se creían combatidos victoriosamente hacía mucho tiempo.

Indica - por usar las palabras que me expresó hace unos pocos meses por cartaque "debe acabarse pronto con los huevos de dragón del panteísmo hegeliano $[\ldots] " 13$.

\footnotetext{
${ }^{12}$ Carl Friedrich Göschel, op. cit., p. 65

${ }^{13}$ Christian Carl Josias von Bunsen, Aus seinen Briefen und nach eigener Erinnerung geschildert von seiner Witwe. Zweiter Band: Schweiz und England, Leipzig, Brockhaus, 1869, p. 133.
} 
Como muy acertadamente afirmaba Heine, el renovado pensamiento religioso conservador era el único capaz de comprender "el verdadero significado de la cuestión [en torno al panteísmo]" -y se lamentaba- "estos piadosos oscurantistas son por ello los más peligrosos enemigos de nuestro sistema universitario"14. No en vano, Stahl fue el máximo representante del pensamiento de la Restauración y del antihegelianismo ${ }^{15}$, tal como se muestra en su obra Die Philosophie des Rechts nach geschichtlicher Ansicht (183037). Allí, una de las cuestiones tratadas es, precisamente, la de la personalidad divina:

La acusación [de panteísmo] no tiene que ver, en modo alguno, tal y como supone Hegel, con sostener que no hay nada fuera de Dios, con que todas las cosas proceden de él y son en él [...], sino que la acusación tiene que ver con la falta de personalidad de Dios: que Dios en los sistemas filosóficos sea el todo, no se censura, sino que solo sea el todo ${ }^{16}$.

Stahl consideraba así que la filosofía hegeliana y su panteísmo negaban la personalidad divina poniendo en peligro la autoridad del monarca. Por ello, quiere restaurar en su filosofía del derecho la unidad entre autoridad religiosa y Estado prusiano:

\begin{abstract}
Si el Estado se presenta en primer lugar como un reino moral de la comunidad humana, esto es así porque, considerado más profundamente, es al mismo tiempo una institución divina. [...] Por sí mismo ningún hombre puede tener poder de autoridad sobre otro, ni tampoco la comunidad sobre el individuo. Tampoco pueden los hombres fundar el poder de autoridad mediante el contrato, pues no disponen de su vida ni de su libertad. Es el derecho divino de la autoridad ${ }^{17}$.
\end{abstract}

Ahora bien, el punto central de esta fundamentación del Estado en la autoridad divina reside en la personalidad; si Dios es el soberano personal del mundo, análogamente el monarca debe ser el soberano personal del Estado:

El Estado es, como reino moralmente intelectual, un poder de dominación real y libre, pero sobre la base de un orden moralmente entendido. Su gobierno tiene, por ello, un doble elemento: la autoridad del poder estatal (imperium), es decir, el poder que es practicado por el hombre, y la ley (lex). Aquél es el poder de la voluntad personal [...], ésta, la convicción duradera que debe estar

\footnotetext{
${ }^{14}$ Heinrich Heine, Sobre la historia... op. cit., p. 89.

${ }^{15}$ Cfr. Warren Breckman, op. cit., pp. 80-88.

${ }^{16}$ Friedrich Julius Stahl, Die Philosophie... Erster Band, op. cit., p. 464. (De nuevo, nos hemos apoyado en la traducción de Enrique Gil y Robles en: Friedrich Julius Stahl, Historia... op. cit., p. 547).

${ }^{17}$ Friedrich Julius Stahl, Die Philosophie des Rechts. Zweiter Band. Zweite Abteilung. Rechts- und Staatslehre auf der Grundlage Christlicher Weltanschauung, Hildesheim, Georg Olms, 1963, p. 176.
} 
a la base de la verdadera voluntad personal [...]. Mediante las dos el gobierno ha reunido, pues, el carácter completo de la dominación personal ${ }^{18}$.

Especialmente relevante es la obra de Karl Ernst Schubarth, quien en un duro ataque al hegelianismo en Über die Unvereinbarkeit der Hegelschen Staatslehren mit dem obersten Lebens- und Entwicklungsprinzip des Preußischen Staats de 1839, muestra que la filosofía hegeliana es enemiga del Estado prusiano, pues niega la idea de personalidad que está a su base ${ }^{19}$. Ya al comienzo de la obra explica su intención:

Que esta vez dirija mi ataque [a la filosofía hegeliana] desde el punto de vista político se debe principalmente al hecho de que cuando, como prusiano y protestante, me pregunté sobre esta doctrina, nunca llegué al menor acuerdo con ella al respecto [...]. [Incluso] si hubiera podido rendirme ante ella, aunque fuera por una inconsistencia con mi conciencia protestante, no podría haberlo hecho en modo alguno en lo que se refiere al Estado. Como prusiano, para quien el concepto de la monarquía pura, bajo la cual vivo, se identifica con el concepto más elevado que el protestantismo inspira y crea, a saber, el de personalidad, no estoy en condiciones [de mostrarme de acuerdo] a este respecto [con la filosofía hegeliana $]^{20}$.

Para Schubarth, la personalidad de Dios no puede esconderse detrás del mundo como "el diablo": "El Dios hegeliano, como negación que tiene que superarse, debe pedir sumisamente al diablo que le sea de ayuda para [alcanzar] su existencia más alta" ${ }^{21}$. La monarquía constitucional como resultado último de la doctrina hegeliana del derecho, como forma más verdadera y real del Espíritu, no es otra cosa, según Schubarth, que "una república disfrazada de monarquía, ni más ni menos" ${ }^{22}$, en la que se restringe "la personalidad del príncipe y su efectividad [...] a la mera capacidad de poder decir "sín" o firmar con su nombre" ${ }^{23}$; y por lo tanto, lo convierte en un mero "maestro de ceremonias". Más bien, el autor piensa que

[e]ste desmoronamiento de la personalidad [...] es muy contrario al concepto de monarquía pura y al Estado personal que ésta establece. La sustancia del Estado prusiano, como monarquía pura, es esencialmente solo su familia gobernante [...]; de modo que la existencia del Estado se basa principalmente en aquello que Hegel llama la peculiaridad del carácter, de la que, según él, nada debería depender ${ }^{24}$.

\footnotetext{
${ }^{18}$ Ibidem, pp. 186-188.

${ }^{19}$ Cfr. Warren Breckman, op. cit., p. 10.

${ }^{20}$ Karl Ernst Schubarth, Über die Unvereinbarkeit der Hegel'schen Staatslehre mit dem obersten Lebens- und Entwickelungsprinzip des Preußischen Staats, Breslau, Georg Philipp Aderholz, 1839, p. iv.

${ }^{21}$ Ibidem, p. vi.

${ }^{22}$ Ibidem, p. 9.

${ }^{23}$ Ibidem, p. 12.

${ }^{24}$ Ibidem, p. 15.
}

Araucaria. Revista Iberoamericana de Filosofí, Política, Humanidades y Relaciones Internacionales, año $22, \mathrm{n}^{\circ} 44$. Segundo semestre de 2020. Pp. 107-124. ISSN 1575-6823 e-ISSN 2340-2199 https://dx.doi.org/10.12795/araucaria.2020.i44.05 
Así, concluye que la consecuencia de la visión hegeliana del Estado:

es, en efecto, una invitación a la insurrección y la rebelión en la medida en que tal doctrina despierta la convicción de que [...] el Estado en su configuración actual no es un Estado perfectamente constituido ${ }^{25}$.

También en 1839 el ortodoxo luterano Heinrich Leo publicó su polémico y satírico panfleto Die Hegelingen, en el que distinguía a los verdaderos hegelianos de los "hegelingos" o Junghegelianer. No dudó que, para estos últimos, "las convicciones políticas siempre están determinadas en cierta medida por las religiosas" 26; y que ellos constituyen un "partido" dentro de la filosofía hegeliana caracterizado por sostener las siguientes convicciones:

1) Este partido niega a aquel Dios que es también una persona. [...] [E]ste partido enseña el ateísmo de un modo totalmente público. 2) Este partido niega que la encarnación de Dios en Cristo sea, según su naturaleza, distinta de una encarnación diaria de Dios [....] en cada persona [...]. Este partido enseña de abiertamente que el Evangelio es una mitología. 3) Este partido niega que exista una perduración personal del ser humano tras la muerte [...]. Este partido enseña abiertamente una religión del mero más acá. 4) Este partido, sin embargo, [...] da, a través de un enmascaramiento de sus impías doctrinas [...] la apariencia de ser un partido cristiano, y así se asegura la posibilidad de admisión en los juramentos cristianos y la participación externa en los sacramentos cristianos ${ }^{27}$.

Con la reacción a la obra de Strauß, se puso de manifiesto que el campo de batalla político era, en la Alemania de los años treinta del siglo XIX, el de la religión; y Heinrich Leo desenmascaró la apariencia religiosa que los Junghegelianer habían adoptado para dar cauce a sus ideas políticas liberales. Pero ¿quién fue el máximo representante de esta filosofía política enmascarada?; ¿cómo se articularon en ella el panteísmo y las ideas políticas liberales tan duramente atacadas por los teólogos políticos de la Restauración?

\section{EI trueno que sigue al rayo. El panteísmo como locus revolucionario}

Desde la seguridad de la vecina Francia, un poeta -si bien un poeta hegeliano-, profetiza la revolución panteísta: Heinrich Heine. Este hegeliano será el mayor exponente y el resultado teórico más claro de la tradición que

\footnotetext{
${ }^{25}$ Karl Ernst Schubarth, op. cit., p. 16.

${ }^{26}$ Leo, H.: Die Hegelingen. Actenstücke und Belege zu der s. g. Denunciation der ewigen Wahrheit, Halle, Eduard Anton, 1839, p. 91.

${ }^{27}$ Ibidem, pp. 2 y s.
} 
arranca, como vimos en la primera parte de este artículo, en el siglo XVI y que llega hasta mediados del XIX.

En él, es clara la conciencia de que a partir de los pensamientos, de las construcciones filosóficas, debe surgir una praxis efectiva. Tomando como punto de partida, sin duda, la Revolución Francesa, integra en su discurso el saint-simonismo, la filosofía de la acción de los Junghegelianer, la crítica a la religión de Feuerbach y a "Hegel mismo[, quien] sería finalmente como el rayo, que se adelanta al trueno de una terrible revolución alemana"28. Heine supo ver en este último a un revolucionario encubierto que representaba el punto álgido de una libertad que venía desarrollándose en la historia alemana desde Lutero.

5. a) El profeta del panteísmo revolucionario. Heinrich Heine y el "secreto a voces" de Alemania.

Heinrich Heine encontró en la síntesis filosófico-religiosa del panteísmo hegeliano una revolución espiritual que sería el reflejo de la revolución material -real- que tuvo lugar en 1789 y en 1830 en Francia. Por ello, un año después de la Revolución de Julio afirma:

[...] soñábamos a nuestra manera alemana, esto es, filosofábamos. [...] Lo curioso es que el impulso práctico de nuestros vecinos del otro lado del Rin tenía, con todo, una afinidad electiva propia con nuestros sueños filosóficos en la tranquila Alemania. [...] Los franceses [...] nos habían rogado dormir y soñar por ellos, y nuestra filosofía alemana no es, según ellos, otra cosa que el sueño de la Revolución Francesa ${ }^{29}$.

Esto último es importante: es el punto de partida para considerar las aventuras y desventuras del proyecto político revolucionario alemán; pues, según Heine, si los alemanes sueñan, es porque se han dormido y deben despertar.

En Sobre la historia de la religión y la filosofía en Alemania (1834), la revolución no puede empezar en el país germano con el materialismo, como en Francia, sino con una concepción religiosa del mundo y del ser humano que sea adecuada al espíritu del pueblo tudesco: el panteísmo. "En Alemania" -afirma el poeta- "es imposible una revolución general mientras los principios de ésta no se deduzcan de una filosofía más popular, más religiosa y más alemana [que el materialismo], y se imponga por fuerza de esas raíces" ${ }^{30}$. Que esto sea

\footnotetext{
${ }^{28}$ Jürgen Habermas, "Heine y el papel de los intelectuales en Alemania (1987)" en Heinrich Heine, Sobre la historia ... op. cit., p. 254.

${ }^{29}$ Heinrich Heine, "Introducción al escrito de "Kahldorf sobre la nobleza, en cartas al conde M. von Moltke (1831)" en Heinrich Heine, Sobre la historia ... op. cit., p. 226.

${ }^{30}$ Heinrich Heine, Sobre la historia... op. cit., p. 108n (nota manuscrita añadida en la segunda edición de 1852).
} 
así, se debe para Heine a que, en primer lugar, el retorno del panteísmo como filosofía popular no supondría otra cosa sino la superación histórica de una doble problemática consistente, en primer lugar, en que el cristianismo habría profanado y usurpado el lugar de la religión originaria de Alemania. Así lo expresa cuando afirma:

La fe nacional europea, más acusadamente en el norte que en el sur, era la panteísta: $[\ldots]$ el mundo fenoménico entero estaba deificado; el cristianismo invirtió completamente esa concepción y colocó en el lugar de una naturaleza deificada otra diabolizada ${ }^{31}$.

Asimismo, en segundo lugar, el cristianismo habría separado la naturaleza del espíritu, lo real de lo ideal, el alma del cuerpo.

En esta raíz doble encontraría su origen, según Heinrich Heine, la actual situación alemana y europea: cuando el cristianismo se convirtió en el núcleo espiritual del pueblo, se reveló como una religión que quería "el dominio absoluto de esta tierra", pero al mismo tiempo, debido a aquella escisión entre espíritu y materia, demostró ser también una fe "demasiado sublime, demasiado pura, demasiado buena para esta tierra"32. Por esta razón habría fracasado estrepitosamente como religión ordenadora del mundo: impotente, entregó "la odiada espada y el despreciado dinero", es decir, "la materia, lo mundanal, a las manos del César". Sin embargo, en esta situación el cristianismo no solo habría delegado el dominio sobre la materialidad a los poderes mundanos, sino que también se habría visto obligado a convertirse en su aliado:

los representantes del espíritu tienen que acabar por entenderse con ellos. No solo los romanos, sino también los ingleses y los prusianos, todos los sacerdotes privilegiados $[\ldots]$ se han aliado con César y sus consortes para la opresión de los pueblos ${ }^{33}$.

Así cayó la noche sobre Alemania; y los alemanes durmieron. Pero por fortuna también pudieron soñar; pues aquella doble escisión -piensa Heine- no se realizó completamente:

el hombre no abandona gustosamente aquello que fue caro y amable para sus antepasados, y algunos sentimientos se aferraron secretamente a ello a pesar de encontrarlo corrompido y deformado. Por eso aquella deformada creencia popular se ha revelado en Alemania acaso más duradera que el propio cristianismo ${ }^{34}$.

\footnotetext{
${ }^{31}$ Heinrich Heine, Sobre la historia ... op. cit, p. 63.

${ }^{32}$ Ibídem, p. 119.

${ }^{33}$ Ibídem, p. 120

${ }^{34}$ Ibidem, p. 71.
} 
Esto último es lo que explicaría por qué el panteísmo pudo permanecer soterrado tanto tiempo hasta su resurgimiento en el siglo XIX.

Ahora bien, fue necesario un largo periplo de liberación para que los alemanes pudiesen soñar de nuevo con esa "doctrina que tan misteriosamente atrae al espíritu alemán" 35 . Heine señala el comienzo de la andadura con Lutero, quien en su pugna con la Iglesia católica desembarazó a los alemanes de las autoridades de Roma, instituyó "la libertad de pensamiento" como "un derecho protestante" ${ }^{36}$ y fundó la lengua alemana: "Martín Lutero" -señala Heine- "no nos dio solo la libertad de movernos, sino también el medio para ello: dio un cuerpo al espíritu. Dio la palabra al pensamiento. Creó la lengua alemana" ${ }^{{ }^{37}}$. Sin embargo, no fue hasta Kant cuando la intelectualidad alemana pudo librarse de los dogmas cristianos que la atenazaban. El poeta hegeliano es tajante al respecto: la Crítica de la razón pura fue "el 21 de enero del deísmo" ${ }^{38}$. Kant fue el Robespierre espiritual de Alemania, ya que del mismo modo que los franceses le cortaron la cabeza a Luis XVI y a los antirrevolucionarios, Kant había descabezado el deísmo: "la naturaleza les había destinado [a Robespierre y a Kant] a pesar café y azúcar, pero el destino quiso que pesaran otras cosas y puso un rey en la balanza de uno y un Dios en la de otro" 39 .

Tras Kant, la filosofía panteísta alzó el vuelo: Fichte fue "el ateo" que amó la libertad ${ }^{40}$; Goethe, "el Spinoza de la poesía" ${ }^{41}$; y Schelling, el defensor del "universo divino de Spinoza", del "Dios-Universo" "42. Tras ellos, señala Heine, "[n]uestra revolución filosófica ha terminado. Hegel ha cerrado su gran ciclo"43. con Hegel se produjo entonces la sistematización del panteísmo, su desarrollo y su ampliación; él fue, en última instancia su "ordenador y custodio"44.

Tras ellos, los alemanes dejarían de soñar, el panteísmo dejaría de ser única y exclusivamente una cuestión filosófica y espiritual, y se reconciliaría -violentamente- con la materia: "solo una vez consumada esta [revolución filosófica] podía pasar [Alemania] a la revolución política"45, pues solo mediante

${ }^{35}$ Ibídem, p. 128.

${ }^{36}$ Ibídem, p. 88.

${ }^{37}$ Ibídem, p. 90. En esta tradición liberadora, Heine coloca también a Christian Wolff como el Lutero literario de la filosofía, pues "la expuso en lengua alemana". Por eso dice de él: "su mérito consiste más bien en que nos estimuló a todos a filosofar en nuestra lengua materna. Como no supimos tratar la teología sino en latín hasta Lutero, así también nos ocurrió con la filosofía hasta Wolff" (Ibidem, p. 126).

${ }^{38}$ Ibídem, p. 149.

${ }^{39}$ Ibidem, 155.

${ }^{40}$ Ibídem, p. 173.

${ }^{41}$ Ibidem, p. 182.

${ }^{42}$ Ibídem, pp. 197 y s.

${ }^{43}$ Ibidem, p. 203.

${ }^{44}$ Cfr. Dorf Sternberger, "Heine y la revolución alemana(1972)" en Heinrich Heine, Sobre la historia... op. cit., p. 248.

${ }^{45}$ Heinrich Heine, Sobre la historia ... op. cit. p. 206.

Araucaria. Revista Iberoamericana de Filosofí, Política, Humanidades y Relaciones Internacionales, año $22, \mathrm{n}^{\circ} 44$. Segundo semestre de 2020. Pp. 107-124. ISSN 1575-6823 e-ISSN 2340-2199 https://dx.doi.org/10.12795/araucaria.2020.i44.05 
aquella se pueden "conjurar las fuerzas del antiguo panteísmo germano"46; "fuerzas revolucionarias que solo esperan el día en que puedan mostrarse y llenar el mundo de admiración y espanto" ${ }^{4}$. Llegará el momento -profetiza Heine- en que la "religión secreta de los alemanes" dé sus verdaderos frutos:

No os riais del fantasioso que espera en el terreno de los hechos la misma revolución que ha tenido lugar en el reino del espíritu. El pensamiento precede a la acción como el rayo al trueno. [...] Se representará entonces en Alemania una pieza en comparación con la cual la Revolución Francesa parecerá un idilio inocente ${ }^{48}$.

5.b) La articulación de la revolución política y social a través del panteísmo

Heinrich Heine, en la línea de su condena al cristianismo, muestra su desprecio por cualquier concepción personalista de Dios: "Somos mayores de edad y no necesitamos cuidados paternales. Y tampoco somos espartanos, obra de un gran mecánico. El deísmo es una religión para esclavos, para niños, para ginebrinos y para relojeros"49, pues representa un Dios que "gobierna el mundo desde arriba, como se gobierna una institución realmente distinta de su gobernante" ${ }^{50}$.

Frente al deísmo y al teísmo de la obediencia y la renuncia al mundo, el panteísmo abre para Heine las puertas a la emancipación del ser humano. La humanidad entera constituye, según él, la encarnación de Dios; cada pueblo muestra una porción del cosmos divino que en él se manifiesta; el sujeto de la historia es Dios a través del hombre. Por ello afirma:

Dios se manifiesta, empero, del modo más magnífico en el hombre, el cual siente y piensa a la vez, sabe diferenciarse individualmente de la naturaleza objetiva y lleva ya en su razón las ideas que se manifiestan en el mundo visible. Pero esto no ocurre en el individuo y por el individuo, sino solo en y por la totalidad de los hombres: de modo que todo hombre no es más que una parte del universo divino, la concibe y la representa, mientras que todos los hombres juntos concebirán y representarán el universo divino entero en la idea y en la realidad $^{51}$.

Las consecuencias que se siguen inmediatamente de esto es que el panteísmo es una religión de la acción, pues "la conciencia de su divinidad

\footnotetext{
${ }^{46}$ Ibidem, p. 208.

${ }^{47}$ Ibidem, p. 207.

48 Ibídem, pp. 208 y s.

49 Ibidem, p. 125.

${ }^{50}$ Ibidem, p. 118.

51 Ibidem, p. 122.
}

Araucaria. Revista Iberoamericana de Filosofia, Política, Humanidades y Relaciones Internacionales, año $22, \mathrm{n}^{\circ} 44$. Segundo semestre de 2020. Pp. 107-124. ISSN 1575-6823 e-ISSN 2340-2199 https://dx.doi.org/10.12795/araucaria.2020.i44.05 
entusiasmará al hombre y le moverá a manifestarla, y así se producirán entonces las verdaderas hazañas del verdadero heroísmo, que magnificarán la tierra"52. Esta acción es esencialmente política y debe ser llevada a cabo mediante "una democracia de dioses de iguales derechos, igual santidad [e] igual felicidad" 53 ; y este último rasgo, el de la felicidad, es el que muestra su relevancia social: la acción política democrática y libre debe traer consigo igualdad y bienestar. El panteísmo, al suprimir la escisión entre Dios y creatura, revaloriza el mundo: "tanto materia cuanto espíritu, una y otro son igualmente divinos, y el que ofende la santa materia es tan pecador como el que peca contra el Espíritu Santo" 54 . Debido a esto -asegura Heine- "nuestras nuevas instituciones" surgidas de la revolución política panteísta, deben procurar la reconciliación de espíritu y materia re-santificando esta última para el interés general, es decir, deben buscar "el bienestar de la materia, la felicidad material de los pueblos" 55 . Por ello, Heine concluye:

La gran palabra de la Revolución, pronunciada por Saint-Just -le pain est le droit du peuple-, suena para nosotros así: le pain est le droit divin de l'homme. Nosotros no luchamos por los derechos humanos del pueblo, sino por los derechos divinos del hombre ${ }^{56}$.

\section{Conclusión. La ultima ratio regis y el triunfo de la Restauración.}

Los huevos de dragón del panteísmo hegeliano eclosionaron en 1848 y de ellos surgieron tanto las luchas callejeras de los socialistas y la izquierda hegeliana más radical como el Vorparlament de Frankfurt, en el que participó un buen número de Junghegelianer -también un hegelianismo más moderado. La Revolución de Marzo supuso así el zenit, pero también la abrupta clausura histórica de una corriente filosófica y político-religiosa nacida en el siglo XVI como una suerte de Reforma "insatisfecha", transfigurada por el spinozismo clandestino en el XVII y XVIII, y desarrollada en el XIX como panteísmo hegeliano.

La Paulskirchenverfassung de 1848, elaborada en la Asamblea Constituyente elegida por sufragio universal masculino en Frankfurt y ofrecida -sin éxito- para su sanción a Federico Guillermo IV, suponía el intento de realización del conjunto de los anhelos liberales; su sección sexta otorgaba a los ciudadanos una serie de derechos que ningún Estado alemán podía violar

\footnotetext{
52 Ibidem, p. 123.

53 Ibidem, p. 124.

54 Ibidem, p. 118.

${ }^{55}$ Ibidem, p. 123.

56 Ídem.
} 
o revocar: libertad de residencia y propiedad, libertad de opinión (de palabra, escritura o representación pictórica), libertad de prensa, libertad de elección y ejercicio de profesión, libertad religiosa y de conciencia, de su práctica, así como el derecho a mantenerla en secreto. También otorgaba derecho a la propiedad, derecho a la enseñanza primaria gratuita, y derecho de reunión y asociación. Garantizaba asimismo la igualdad ante la ley, la publicidad de los juicios, la inviolabilidad y secreto de la correspondencia, y la inviolabilidad del domicilio. Igualmente, ponía fin a los derechos nobiliarios y a las relaciones de servidumbre y esclavitud; así como también a la pena de muerte. Por último, separaba Iglesia y Estado al sancionar que no existía ninguna Iglesia oficial.

El Dios panteísta del hegelianismo intentó realizarse en la historia, reconciliarse y reconocerse en el mundo; pero éste no lo permitió. 1848 no solo fue el año de los argumentos espirituales, sino también el de los contraargumentos materiales: el plomo de los soldados prusianos y austríacos aplicaron la ultima ratio regis y la disputa entre panteísmo revolucionario y personalismo divino restauracionista quedó zanjada mediante el uso de la fuerza.

Una vez sofocada la Revolución de Marzo, la persecución del panteísmo continuó más allá de la censura -buena prueba de ello es el caso del exhegeliano convertido al neokantismo Kuno Fischer, a quien le fue retirada la venia legendi y fue expulsado de la Universidad de Heidelberg en 1853 tras ser acusado públicamente de panteísmo ${ }^{57}$-; y los pensadores progresistas tuvieron que recurrir, otra vez, a nuevas estrategias de encubrimiento -así procederían precisamente los neokantianos-, a la autocensura e incluso al exilio. Sin embargo, los logros de esta tradición y su resultado político, la Constitución de Frankfurt, no caerían en el olvido: sus conquistas y avances servirían posteriormente de inspiración para la Constitución de Weimar de 1919 y para la Constitución de la República Federal Alemana de 1949.

${ }^{57}$ Cfr. Frederick C. Beiser, The Genesis of Neo-Kantianism, Oxford University Press, 2014, pp. 229 y s. Fischer en sus lecciones universitarias había proclamado que "para la filosofía, racionalismo y panteísmo son lo mismo; [pues] la filosofía dice que debemos conocer, el racionalismo dice que debemos conocer mediante conceptos y el panteísmo dice que el dios concebido o conocido es el orden eterno" (Kuno Fischer, Geschichte der neuern Pilosophie. Erster Band. Das classische Zeitalter der dogmatischen Philosophie, Mannheim, Basserman \& Mathy, 1854, 553 y s.). 


\section{Referencias bibliográficas}

\section{A. Fuentes primarias}

Karl Friedrich Bachmann, Anti-Hegel, Jena, Crokescher Buchhandlung, 1835. Christian Carl Josias von Bunsen, Aus seinen Briefen und nach eigener Erinnerung geschildert von seiner Witwe. Zweiter Band: Schweiz und England, Leipzig, Brockhaus, 1869.

Kuno Fischer, Geschichte der neuern Pilosophie. Erster Band. Das classische Zeitalter der dogmatischen Philosophie, Mannheim, Basserman \& Mathy, 1854.

Eduard Gans, "Ueber die Unvereinbarkeit der Hegel'schen Staatslehre mit dem obersten Lebens- und Entwickelungsprincip des preussischen Staats; von Dr. K.E.E. Schubarth. Breslau, 1839. Bei Georg Philipp Aderholz. 30 S. in 8" en Jahrbücher für Wissenschaftliche Kritik, 25-26 (febrero de 1839), pp. 199-208.

Carl Friedrich Göschel, Beiträge zur spekulativen Philosophie von Gott und dem Menschen und von dem Gott-Menschen. Mit Rucksicht auf Dr. D. F. Strauss Christologie, Berlín, Duncken und Humboldt, 1838.

Heinrich Heine, Sobre la historia de la religión y de la filosofía en Alemania, Madrid, Alianza, 2008.

Heinrich Leo, Die Hegelingen. Actenstücke und Belege zu der s. g. Denunciation der ewigen Wahrheit, Halle, Eduard Anton, 1839.

Carl Ludwig Michelet, Vorlesungen über die Persönlichkeit Gottes und Unsterblichkeit der Seele oder die ewige Persönlichkeit des Geistes. Gehalten an der Friedrich-Wilhelms-Universität zu Berlin im SommerhalbJahre 1840, Berlin, Ferdinand Bümmler, 1841.

Karl Ernst Schubarth, Über die Unvereinbarkeit der Hegel'schen Staatslehre mit dem obersten Lebens- und Entwickelungsprinzip des Preußischen Staats, Breslau, Georg Philipp Aderholz, 1839.

Friedrich Julius Stahl, Die Philosophie des Rechts. Erster Band. Geschichte der Rechtsphilosophie, Hildesheim, Georg Olms, 1963.

-- Die Philosophie des Rechts. Zweiter Band. Zweite Abteilung. Rechts- und Staatslehre auf der Grundlage Christlicher Weltanschauung, Hildesheim, Georg Olms, 1963.

-- Historia de la filosofía del derecho, Madrid, La España Moderna, s.a.

David Friedrich Strauß, Die christliche Glaubenslehre in ihrer geschichtlichen Entwicklung und im Kampfe mit der modernen Wissenschaft dargestellt. Erster Band, Tübingen/Stuttgart, C.F. Osiander/F. H. Köhler, 1840. 


\section{B. Estudios}

Frederick C. Beiser, The Genesis of Neo-Kantianism, Oxford University Press, 2014.

Warren Breckman, Marx, the Young Hegelians, and the Origins of Social Theory. Dethroning the Self, Cambridge, Cambridge University Press, 2001.

Félix Duque, La Restauración. La escuela hegeliana y sus adversarios, Madrid, Akal, 1999.

Jürgen Habermas, "Heine y el papel de los intelectuales en Alemania (1987)" en Heinrich Heine, Sobre la historia... op. cit., pp. 252-255.

Domenico Losurdo, Hegel, Marx e la tradizione liberale. Libertà, uguaglianza, Stato, Roma, Editori Riuniti, 1988.

Dorf Sternberger, "Heine y la revolución alemana (1972)" en Heinrich Heine, Sobre la historia... op. cit., pp. 248-251. 